\title{
An audit of the teachers' views on student disrespect in a medical school
}

${ }^{1}$ Department of Medicine, ${ }^{2}$ Unit of Community Medicine, Faculty of Medicine, AIMST University, 08100, Semeling, Bedong, Kedah, Malaysia.

For Correspondence

${ }^{*} D$ r. Sethuraman K.R,

Email:kr.sethuraman@aimst.edu.my

Date of

Submisssion: 23-01-2019

Acceptance: 26-02-2019

Access this article online

Quick Response Code

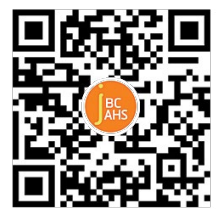

https://www.jbcahs.org

\section{Sethuraman K.R ${ }^{1, *}$, Swe Swe Latt ${ }^{2}$}

\section{ABSTRACT}

Background and Objectives: Student disrespect in higher education is a topic of increasing focus in recent times. This internal audit on faculty perception of student disrespect was conducted among the staff from the Faculty of Medicine in northern Malaysia.

Material and Methods: A cross-sectional audit was done among the 95 staff of a private university using the online Google-form as voluntary and anonymous in nature. The descriptive statistics and inferential statistics were done by SPSS software.

Results: The total number of respondents were $72(76 \%)$. Of the eight responders $(11 \%)$ who perceived student disrespect, seven of them perceived it among the students in clinical years. There was no significant association between the gender of the respondent and the perception on student disrespect. The themes of student disrespect were 'not following rules; not being punctual, lack of social grace or etiquette and absenteeism without prior notice'.

Conclusion: Several studies have documented that incivility and disrespectful behaviour are often displayed in the clinical environment, which might adversely affect patient safety and promote medical students' disrespect. For the medical students to learn proper behaviour by role-modelling, the medical educators and professionals must eschew rudeness and incivility in the workplace.

\section{Keywords:}

Incivility, student behaviour, clinical environment, role-modelling

\section{INTRODUCTION}

Disrespect in academic institutions refers to the lack of regard for the feelings, wishes or rights of others, viz., peers, teachers and the other staff and students. Some other words that conveys disrespect are: incivility, impoliteness, bad manners, lack of consideration, contempt, scorn, disregard, disdain, mockery, ridicule, rudeness, insolence, impertinence, flippancy, etc. Many opinion polls have revealed that student disrespect is on the rise. ${ }^{1}$

A quick search for 'student disrespect' in the 'ProQuest' database yielded only 0-7 articles per decade from the 1920's to the 1970's; however, in the past 4 decades it has sky rocketed from 15 in the 80 's to 186 in the 90's, 780 in 2000-'09 and
1139 since $2010 .{ }^{1}$ Therefore, there is strong evidence to support the claims of student disrespect being on the rise. Teherani et al categorized various unprofessional behaviors exhibited by medical students while they performed clinical examinations. ${ }^{2}$

This study undertook a preliminary internal audit on this apparently global issue in the Faculty of Medicine situated in a rural private University in northern Malaysia.

\section{MATERIAL AND METHODS}

We undertook an initial survey among the faculty staff of a medical school with nearly 1000 medical students to see the extent of student disrespect as perceived by the staff. A 
cross-sectional survey was done during October 23 to 30, 2018 among the staff of the Faculty of Medicine, AIMST University, Malaysia using the online Googleform. The convenience samples responding to the survey were voluntary and anonymous in nature. Respondents could submit the form only once using their institutional e-mail id.

In the self-constructed questionnaire, section $\mathrm{A}$ consisted a) nature of the job: teaching/non-teaching; b) current position: demonstrator, lecturer, senior lecturer, associate professor, senior associate professor, professor, senior professor, non-teaching office-staff and others; c) nationality: Malaysian or Expatriate staff; d) gender; e) type of work: clinical, pre-clinical, both, administrative staff, non-teaching staff and others; f) students handled: medical students of year 1 to year 5 and students from other faculties, viz., dentistry, pharmacy, physiotherapy; g) "Do you feel that your students disrespect you?" with two options as 'yes' or 'no'. If the respondent answered 'no', the e-form reached the end and just needed a click to be submitted.

To the item " $\mathrm{g}$ ", if the respondent had responded with a 'yes', the e-form opened section B. The questions in the section B were, a) "In which faculty have you felt students' disrespect?" with answering options of 'Faculty of Medicine (FOM)' or 'other faculty'; b) "If they are from FOM, which students are more disrespectful?" with options on 'clinical students' or 'pre-clinical students'; c) "Can you cite 2 or 3 examples of students' disrespect that you have experienced?" permitting an open response; $d$ ) "What is the proportion of disrespectful students?" to be answered as estimatedpercentage; e) "Do you have any suggestions to solve this problem?" permitting an open response. Some questions (c, d, e) were optional, which the respondent could skip and submit the Google form online.

This survey was an internal audit, voluntary and totally anonymous in nature. The proposal was approved by consensus during a staff meeting. In our faculty, an internal audit that has no ethical issue per se, need not be submitted for IRB clearance.

Descriptive analysis was initially done by Google forms analytics. The descriptive statistics were shown as frequency and percentages. This was transferred to SPSS (2017 version) and further analyzed. Fisher's exact test was used to analyze the association between the gender and the perception on student disrespect with the $\mathrm{p}$ value less than 0.05 as significant level.

\section{RESULTS}

Out of the 95 staff on duty during the study period, 72 responded $(76 \%)$ to this survey. Almost all the respondents were teaching staff $(n=71)$ and only one was a non-teaching staff. There were 13 Professors, 11 Senior Associate Professors, 17 Associate Professors, 17 Senior Lecturers and 14 Lecturers respectively. The International staff were 59 in number and the remaining 13 were Malaysians; there were 42 male and 30 female staff. The respondents who were teaching clinical students were 29 , pre-clinical students were 34 and teaching both clinical and pre-clinical students were nine.

Student disrespect was reported by only eight respondents (11\%); seven respondents identified the

Table 1: Student disrespect mentioned by seven teachers

\begin{tabular}{|c|c|}
\hline $\begin{array}{l}\text { Teacher } \\
\text { Code }\end{array}$ & Examples of student disrespect \\
\hline $\mathrm{T}-1$ & $\begin{array}{l}\text { Going out during class without permission. Using } \\
\text { Hand-phone during class. Eating during lecture } \\
\text { time. }\end{array}$ \\
\hline T-2 & $\begin{array}{l}\text { Parking their cars in Staff parking Zone and } \\
\text { moving the sign board that says Staff Parking. } \\
\text { Not coming to class on time. Walking in and out } \\
\text { of class during the lecture. Eating and drinking in } \\
\text { the class during lectures. }\end{array}$ \\
\hline T-3 & $\begin{array}{l}\text { Using hand-phone in front of me during small } \\
\text { group discussion and when I told him to pay } \\
\text { attention or otherwise to go outside of class, he } \\
\text { just walked out'. 'Those who refuse to adhere to } \\
\text { the class room etiquette, rules and regulations or } \\
\text { instructions given in the student-handbook }\end{array}$ \\
\hline $\mathrm{T}-4$ & $\begin{array}{l}\text { May be, I am wrong in my expectation of respect } \\
\text { from the current-day students, and in comparing } \\
\text { my previous experiences with the students in my } \\
\text { own country: I need to adjust and understand } \\
\text { the socio-cultural back ground of present-day } \\
\text { students. Many times, my own mentees, who } \\
\text { were quite respectful in year-2, when they get } \\
\text { promoted to year-3, pretend as if I am a stranger } \\
\text { whom they never knew! The students of other } \\
\text { faculties seem to be better behaved when } \\
\text { compared to our own students. }\end{array}$ \\
\hline T-5 & $\begin{array}{l}\text { Not being Punctual, not following teacher's } \\
\text { instructions in the class, absenting from a class } \\
\text { without prior notice or apology, poor attitude, not } \\
\text { properly dressed (not wearing tie or name tag, } \\
\text { excessive use of cosmetics or jewellery) not } \\
\text { followed' }\end{array}$ \\
\hline $\mathrm{T}-6$ & $\begin{array}{l}\text { Talking during class. Not wishing the teacher. } \\
\text { Indifference to the proceedings }\end{array}$ \\
\hline $\mathrm{T}-7$ & $\begin{array}{l}\text { They don't greet even we are crossing face to } \\
\text { face; sometimes even if they are my mentees. I } \\
\text { tried to look at them with a smiling face, but they } \\
\text { act like they don't know me at all. Perhaps it is not } \\
\text { disrespect; they are trying to ignore my presence }\end{array}$ \\
\hline
\end{tabular}


disrespectful students as 'students in clinical years, faculty of medicine' and one respondent recognized as 'pre-clinical student from other faculty'. There was no significance association between the gender of the respondent and the perception on student disrespect to them $(\mathrm{p}=0.71)$.

The perception of the eight respondents on the percentage of students showing disrespect in the faculty of medicine (in ascending order) were 10, 10, 15, 40, $40,40,50$ and $80 \%$ respectively.

Open responses on examples of student disrespect mentioned by seven of the respondents are given in Table 1.

The themes of student disrespect were 'not following rules; not being punctual, lack of social grace or etiquette and absenteeism without prior notice'.

The suggestions from five respondents (T-1 to T-5) on how to handle disrespect from the students are given below

T-1: 'Change should happen in the Foundation year before they join the professional course.'

T-2: 'If you put up a rule you should be able to enforce it. Security department must clamp all the student vebicles parked in staff parking zone. All the rules in the Student Handbook must be strictly enforced especially those regarding attendance, dress code, payment of fees. Our students have total disdain to the rules, which is disrespect towards the university which is not acceptable.

T-3: 'Lecturers should be more familiar with the students and let them to understand what we want and why we want them to be a professional doctor'.

T-4: 'Doctors should be always friendly with their patients and other people. The students should learn to practice it'.

T-5: 'Should take appropriate action on disrespectful students and counsel them.'

\section{DISCUSSION}

The professional behaviour and disrespect shown by medical students are at present an active area of study among the medical educators and in the recent literature. ${ }^{3}$ In 2009, the General Medical Council (UK) has released a document on the professional values, including respectful behaviour to be developed by medical students to make them fit for clinical practice. ${ }^{4}$ In our study, in the anonymous feedback, only $11 \%$ (8 of 71 ) reported student disrespect. The others presumably either condoned the minor aberrations from some of the students or were able to elicit respectful behaviour from their students. Majority of our teaching staff are seniors recruited from South Asia, who have vast experience in class-room management and tactful handling of students that earns their respect.

A survey in Dundee on the student-behaviour compared the perceptions of the public with those of the medical students and the doctors; it has reported that the public tend to assess the medical students' behaviour more critically than the doctors or the students do. The students were more lenient on their own behaviour than what was perceived by the supervising doctors. ${ }^{5}$ Another study has suggested that when compared with the faculty concerns, the students seem to be less bothered about respect for rules, such as avoid copying (plagiarism) or falsifying signatures, etc. ${ }^{6}$

A study done in 2010, have suggested that the predominant use of social media network by the current medical students might be making it difficult for them to distinguish between personal versus professional life, and between acceptable and unacceptable behavioral norms. $^{7}$

While analyzing the behaviour of the current medical students, it is necessary to record their own perceptions on respect and disrespect experienced by them. Karnieli-Miller et al have analyzed 595 reports of professional and unprofessional behaviors witnessed by 152 medical students during their third year of study. ${ }^{8}$ Nearly $25 \%$ of them were on respect; twothirds of these were examples of disrespect, either in the clinical settings or in the class room. They fell in to these 6 categories:

1. Communication (e.g., belittling, being insensitive or blunt and not respecting confidentiality)

2. Bedside behaviours (e.g., making a phone call, wearing gloves while checking pulse or BP)

3. Patient centeredness (e.g., discounting patients' preferences, decisions and needs)

4. Treating others as equals (e.g., pass derisive comments about patients or other professionals) 
5. Valuing the others and their experiences (e.g., ignore the opinions or contributions of others)

6. Nurturing students' learning (e.g., judgemental criticism and negative feedback).

The medical students paid attention to the interactions in which disrespectful behaviors were embedded. Some of these provoked the students to write strong reflections. ${ }^{8}$ There is clearly a need for medical educators and other professionals who teach the students to be positive role models in order to inculcate respect and professionalism in them.

The medical professionals, who were the targets of disrespect, had a higher risk of committing a serious medical error during the subsequent month. ${ }^{9}$ The medical students, who felt disrespected during their formative years, were in turn more likely to disrespect their own patients making it an issue of patient safety. ${ }^{10}$ The 'Harvard Medical School Workinggroup on Professionalism' pointed out that disrespect was pervasive in health care settings and that this constituted a significant threat to the patients' safety and wellbeing by affecting the quality of work by the health care workers. The working group pointed out that in the six-sigma industries, e.g., the aviation and nuclear power industries, all the stake holders understood that even a small failure by anyone, if unchecked, could lead to a major catastrophe. Such organizations focused on creating a positive working culture, which included openness, person-centeredness, respect for co-workers, trust, resilience and creativity. The challenge of changing the work-place culture in medical colleges and hospitals must start at the top with medical college deans and hospital chief executives. ${ }^{11,12}$

\section{CONCLUSION}

In an audit of the staff perception of student disrespect conducted in a medical school in rural Malaysia, 8 of 72 responders $(11 \%)$ reported student disrespect displayed by those in their clinical years. Other studies have documented incivility and rude behaviour by medical professionals in clinical environment, which might be negatively influencing the student behaviour. In view of the importance of workplace etiquette in ensuring patient safety, all the key stakeholders need to work towards improving civility and respectful behaviour in medical schools and healthcare facilities.

\section{CONFLICTS OF INTEREST}

None

\section{ACKNOWLEDGEMENT}

The authors gratefully acknowledge the prompt response from the staff of the faculty of Medicine recording their perceptions of Student disrespect and to the Management of the University for the administrative and financial support.

\section{References}

1. Online search in Proquest database for publications on "Student disrespect 1920 to 2018". https://search.proquest.com/health complete/ results/BB8F2ACFF9BA459BPQ/1 [Accessed on 2018 Dec 26)

2. Teherani A, O'Sullivan P, Lovett M, Hauer K. Categorization of unprofessional behaviours identified during administration of and remediation after a comprehensive clinical performance examination using a validated professionalism framework. Med Teach. 2009;31:1007-12.

3. Yates J. "Concerns" about medical students' adverse behaviour and attitude: an audit of practice at Nottingham, with mapping to GMC guidance. BMC Med Educ. 2014;14:196.

4. Professional Behaviour and Fitness to Practise. (e-book) London: GMC, 2016. Online; available from https://www.gmc-uk.org/-/ media/documents/Professional_behaviour_and_fitness_to_ practise_0816.pdf_66085925.pdf [accessed on 2019 Mar 12].

5. Brockbank S, David TJ, Patel L. Unprofessional behaviour in medical students: a questionnaire-based pilot study comparing perceptions of the public with medical students and doctors. Med Teach. 2011;33:e501-8.

6. Roff S, Chandratilake M, Mcaleer S, Gibson J. Preliminary benchmarking of appropriate sanctions for lapses in undergraduate professionalism in the health professions. Med Teach. 2011;33:234-8.

7. Garner J, O'Sullivan H. Facebook and the professional behaviours of undergraduate medical students. Clin Teach. 2010;7:112-5.

8. Karnieli-Miller O, Taylor AC, Cottingham AH, Inui TS, Vu TR, Frankel RM. Exploring the meaning of respect in medical student education: an analysis of student narratives. J Gen Intern Med. 2010;25:1309-14.

9. Paice E, Smith D. Bullying of trainee doctors is a patient safety issue. Clin Teacher. 2009;6:13-7.

10. Moscarello R, Margittai KJ, Rossi M. Differences in abuse reported by female and male Canadian medical students. Can Med Assoc J. 1994;150:357.

11. Leape LL, Shore MF, Dienstag JL, Mayer RJ, Edgman-Levitan S, Meyer GS et al Perspective: a culture of respect, part 1: the nature and causes of disrespectful behavior by physicians. Acad Med. 2012;87:845-52.

12. Leape LL, Shore MF, Dienstag JL, Mayer RJ, Edgman-Levitan S, Meyer GS, et al Perspective: A culture of respect, creating a culture of respect, part 2 the nature and causes of disrespectful behavior by physicians. Acad Med. 2012;87:853-8. 